\title{
Heart Lesion Repair by Fetal Heart Implantation and Chitosan Flap in Rats
}

\author{
Quéron Sébastien ${ }^{1}$, Delrée Paul2 ${ }^{2}$ De Prez Carine ${ }^{3}$, Najar ES ${ }^{4}$, Bergmann Pierre5 ${ }^{5}$ and Coulic Véry ${ }^{5, *}$ \\ ${ }^{1}$ ULB Laboratory of Translational Research, CHU Brugmann, Brussels, Belgium, Hôpital Européen Georges-Pompidou, Paris, France \\ ${ }^{2}$ Institute Pathology and Genetic, Gosselies, Belgium \\ ${ }^{3}$ Department of Pathological Anatomy, CHU Brugmann, Brussels, Belgium \\ ${ }^{4}$ Department of Medical Imaging, CHU Brugmann, Brussels, Belgium \\ ${ }^{5}$ ULB Laboratory of Translational Research, CHU Brugmann, Brussels, Belgium
}

*Corresponding author: Coulic Véry, ULB Laboratory of Translational Research, CHU Brugmann, Brussels, Belgium, Tel: +3271364252; E-mail: very.coulic@chu-brugmann.be; coulic.very@belgacom.net

Received: 01 Jan, 2020 | Accepted: 12 Feb, 2020 | Published: 19 Feb, 2020

Citation: Quéron S, Delrée P, DePrez C, Najar ES, Bergmann P, et al. (2020) Heart Lesion Repair by Fetal Heart Implantation and Chitosan Flap in Rats. Transplant Res J 3(1): dx.doi.org/10.16966/2473-1730.120

Copyright: : (C) 2020 Quéron S, et al. This is an open-access article distributed under the terms of the Creative Commons Attribution License, which permits unrestricted use, distribution, and reproduction in any medium, provided the original author and source are credited.

\begin{abstract}
Background: Injured myocardium reengineering by stem cell culture in-vitro implanted on the injured heart gives promising but controversial results. We explored the possibility to shunt the in-vitro procedure and to implant directly fetal heart, i.e., precursor cells, on the surface of a heart apex lesion in rats.

Methods: Experiments were performed on 141 rats, excluding donors. Fetal Heart Transplantation (FHI) was orthotopic, one-step. Hearts isolated from fetuses aged 14-21 days of in utero development were placed on a precise and easily reproducible lesion induced by cauterization under a biomaterial flap sutured to the neighbor intact myocardium (38 animals). Control series included 43 animals with lesion alone (L), 37 animals with lesion covered by a biomaterial flap alone $(L+C)$ and 23 intact animals. Heart condition was monthly assessed by ECG and ultra-sonography, macro and microscopic investigations up to 13 months post operation.

Results: Orthotopic FHI on the lesion site was well tolerated. ECG remained typical first for acute, then for chronic infarction in all series, except after FHI (some cases in late delays). No arrhythmia was detected. The Ejection Fraction (EF) fell down to $45.8-58 \pm 2 \%$ and remained lower in $L$ series than in the other ones. Functional recovery was observed in $80.6 \%$ of the $\mathrm{FHI}$ cases versus $55.6 \%$ in $\mathrm{L}$ and $65.5 \%$ in $\mathrm{L}+\mathrm{C}$ ones. The distribution of $\mathrm{FE}$ 's during the observation period differed significantly between the series, with the best results in FHI $(p<0.001)$. Morphologically, FHI induced a heart wall thickening at all observation times. Histologically, after month 4-6, it was impossible to ascertain whether the fetal tissue was integrated into the host myocardium.
\end{abstract}

Conclusion: Orthotopic FHI under a chitosan cover significantly improves the heart functional recovery after a severe apical lesion in the rat. A chitosan flap alone has a positive but limited effect.

Keywords: Heart injury; Heart transplantation; Fetal organ implantation; Heart functional investigations

Abbreviations: ARCA: Acute Respiratory and Cardiac Arrest; BW: Body Weight; CR: Cardiac Rhythm; ECG: Electrocardiography; EF: Ejection Fraction; FHI: Fetal Heart Implant; L: Heart Lesion Alone; L+C: Heart Lesion Covered by a Chitosan Flap; L+I+C: Heart Lesion Covered by a Fetal Heart Implant Fixed by a Chitosan Flap; LV: Left Ventricle; LVWT: Left Ventricle Wall Thickness; M: Mean Value; RR: Respiratory Rhythm; SD: Standard Deviation; Tx: transplantation; USI: Ultra Sound Investigation

\section{Introduction}

The prevalence of cardiac diseases with myocardial injury and the cost of their treatment remain significantly high in most countries [1-8]. Conservative treatment only slows the natural course of the pathology development [9]. Surgery, such as valve replacement, septal corrections or coronary arteries shunting, allows improving many situations. Nevertheless cardiac failure following a myocardium injury of different etiologies remains a scientific and public health problem [6-10]. Presently heart transplantation may be performed everywhere in the world and is very efficient. Nevertheless its realization is hindered by the lack of donors and also by some other difficulties, such as optimization of transplant storage before operation, re- innervation and late delay function of the graft [11-15]. To address this question, alternative "minor" transplantations were proposed, such as stem cell, or cardio myoblast implantation directly or after culture in-vitro [16-27]. Though remodeling of the injured heart was often favorably influenced by the presence of implanted stem cells [25-27], difficulties were encountered such as death of the cultures when implanted in the host heart or local arrhythmia when the implants developed [23]. Presently the use of stem cells is available mainly in valve repair [22]. This has arisen questions whether the 
implants boosted the own organism stem cell mobilization or they could replace injured myocardium cells, and, in both cases what was the role of the characteristics and dimensions of the injury itself.

To answer these questions, we have elaborated and tested at short term (30 days) an experimental model of heart lesion, reproducible in dimensions and pathological characteristics (cauterization of the heart apex) [28]. This model was used for further investigating new surgical approaches of infarct treatment, particularly for elaboration of "minor" transplantation surgery and its evaluation.

In this work, we used this model to test whether fetal heart, which can develop into adult-like organism, as many previous works have shown [29-33], could improve recovery after the lesion. Two approaches were possible: either to grow the fetal heart till relative maturity and use a vascularized flap to cover the myocardium injured zone as we have proceeded for oesophagus repair [33]; or to implant the fetal organ on/into the injured myocardium hoping a positive influence of the growing implant on the repairing process from the very beginning of myocardium recovery. Taking into account preliminary results, we realized only the second approach.

\section{Materials and Methods}

The experiments performed consisted in direct implantation of the fetal heart on the lesion site immediately after its creation. 118 rats, all males of Wistar strain, were used. They were aged 4-6 months at the beginning of the experiment with a BW of $410 \pm 50 \mathrm{~g}$. They were displayed into 4 series: lesion alone (43), lesion plus fetal heart implant under a flap (chitosan [34] or other neutral material widely used in cardiac surgery) for fixation (38), lesion covered with chitosan or neutral material alone (37), and intact animals for control [23] (Table 1).

In the series with fetal heart implantation, 50 pregnant rats were used: one per one recipient as a rule.

\section{Surgical Procedures}

Anesthesia: It was induced by Isoflurane inhalation in a ventilator box ( $4 \%$ for $1 \mathrm{~min} / 100 \mathrm{~g} \mathrm{BW})$, followed by intra-peritoneal injections of Natrium pentobarbital (Nembutal'- Ceva Santé animal- Brussels Belgium: $0.1 \mathrm{ml} / 100 \mathrm{~g}$ BW of a solution to $0.075 \mathrm{mg} / \mathrm{dl}$ ) during the surgical procedure. Buprenorphine hydrochloride (TemgesicLaboratoire Schering-Plough-Courbevoie France: $0.2 \mathrm{ml}$ of a $0.05 \%$ solution in intraperitoneal injection) was added for analgesia. Atropine (Lavoisier-Paris-France, $1 \%$ solution, $0.2 \mathrm{ml}$ independently on BW) in subcutaneous injection was administrated at least 5 minutes before intervention to avoid the occurrence of a vagal shock during the further, especially intrathoracic manipulations.

Table 1: Experimental series in orthotopic transplantation of fetal heart on the injured site.

\begin{tabular}{|l|c|c|c|}
\hline \multicolumn{1}{|c|}{ Series } & $\begin{array}{c}\text { Number } \\
\text { of rats }\end{array}$ & $\begin{array}{c}\text { Observation } \\
\text { delays }\end{array}$ & \multicolumn{1}{|c|}{ Investigations } \\
\hline Lesion only & 43 & $\begin{array}{c}\text { up to } 8 \\
\text { months }\end{array}$ & ECG, USI, Histology \\
\hline Lesion+covering & 37 & $\begin{array}{c}\text { up to } 8 \\
\text { months }\end{array}$ & ECG, USI, Histology \\
\hline Lesion+FHI+covering & 38 & $\begin{array}{c}\text { up to } 12 \\
\text { months }\end{array}$ & ECG, USI, Histology \\
\hline Intact control & 23 & $\begin{array}{l}\text { up to } 12 \\
\text { months }\end{array}$ & ECG, USI, Histology \\
\hline Total & $118+23$ & ECG, USI, Histology \\
\hline
\end{tabular}

For intubation of the animals before intrathoracic interventions on the recipient the trachea was cannulated with a $14 \mathrm{G}$ catheter with the help of a laryngoscope (Mac 0 blade-Heine Germany). An anesthesiaventilation machine (Intermed-Penton, Sigma Delta, and UNONetherland-USA) was used during the surgical procedure at a rate of 60 breaths/minute with a tidal volume at $12 \mathrm{ml} / \mathrm{kg}$ and a ventilation pressure of 0 to 20 milli Bars.

Heart lesion: For heart lesion after thoracotomy the heart was exposed. The Cautery high temperature fine tip (Bovie Medical Corporation-USA) was used to induce, by several drop-contacts without any pressure-less than 1 second each-of the tip (standard temperature of $1200^{\circ} \mathrm{C}$ ) with the surface of the heart, a myocardial lesion at the level of the anterior apical zone of the heart (including mainly left ventricle but also parts of septum and right ventricle). As previously mentioned [28], this localization was chosen because it is easy for access, relatively safe, as far as the left ventricle thickness is no less than $2 \mathrm{~mm}$ at diastole, and because the vessels of this zone are terminal, preventing an unexpected extension of the damage through major coronary branches lesions. The surface and the depth of the lesion depended on the total time of the tip contact with the myocardium and were 7-9 $\mathrm{mm}$ in diameter, 1-1.5 $\mathrm{mm}$ in depth. In order to avoid immediate or delayed perforation, the internal muscular layer was left intact (ensured by visual control) (Figure 1A).

Donor management and graft procurement: Donors were fetuses aged 14-20 days in utero, BW from $1 \mathrm{~g}$ (14 cases) to $6 \mathrm{~g}$ (8 cases), mainly $2-5 \mathrm{~g}(\mathrm{M} \pm \mathrm{SD}=3.3 \pm 0.2)$. The anaesthesia and analgesia of the donors were ensured by gravid female slight over dosing $(0.2 \mathrm{ml} / 100 \mathrm{~g}$ of Nembutal). Laparotomy of the gravid female was performed, the uterus exposed and the fetuses extracted. After wide thoracotomy the fetal heart was isolated and placed in a cup with saline at ambient temperature $\left(22^{\circ} \mathrm{C}\right)$. Within $10-30 \mathrm{~min}(15 \pm 5 \mathrm{~min})$ it was transferred to the recipient. In any cases the time between fetal organ procurement and its implantation did not excess $30 \mathrm{~min}(\mathrm{M} \pm \mathrm{SD}: 15 \pm 5 \mathrm{~min})$.

Fetal heart implantation: Immediately after the creation of a heart lesion, one or several fetal hearts (depending of the donor age and the organ volume) were placed on the myocardium wound in such a manner to cover it. Then a flap of biocompatible artificial tissue of \pm 10 $\times 10 \mathrm{~mm}$ was fixed to the healthy part of the recipient heart using a $8^{\circ \circ}$ Ethilon purse shaped suture (Figure 1B). Felt, Contegra, used in cardiac and vascular surgery (rd' PTFE Felt HUVIO 151 - Bard Peripheral Vascular, Inc., Tempe, AZ 85281, USA; and Ansell Healthcare Europe NV, Brussels 153RN105 lot 1205101905), or chitosan ("Kitozyme", Herstal, Belgium) as in previous experiments [33] were used to cover the graft. For control rats, the patch of neutral material was sutured around the lesion without a fetal heart. The thoracic wall wound was then sutured layer by layer with classic separate stitches using

Vicryl $2^{\circ \circ}$ for sternum, $4^{\circ \circ}$ for muscles and diaphragm (if necessary) and running suture $6^{\circ \circ}$ for the skin.

\section{Recipient follow up}

During the operation and the early-first hours-follow-up, the impact of the lesion on the heart function was monitored by a "Pulse Oximeter" (Contec Medical systems Co, Ltd PRC-RP China; CMS508 model) fixed to the hind left leg of the animal. Electrocardiogram (ECG-leads I, II and III), Respiratory Rate (RR) and rectal temperature were registered by a MOUSE MONITOR (Indus Instruments USAUNO-Netherlands). ECG, RC and RR were obtained from 4 needle electrodes subcutaneously inserted in the standard left-right axillar and groin sites, the rat being in supine position. 

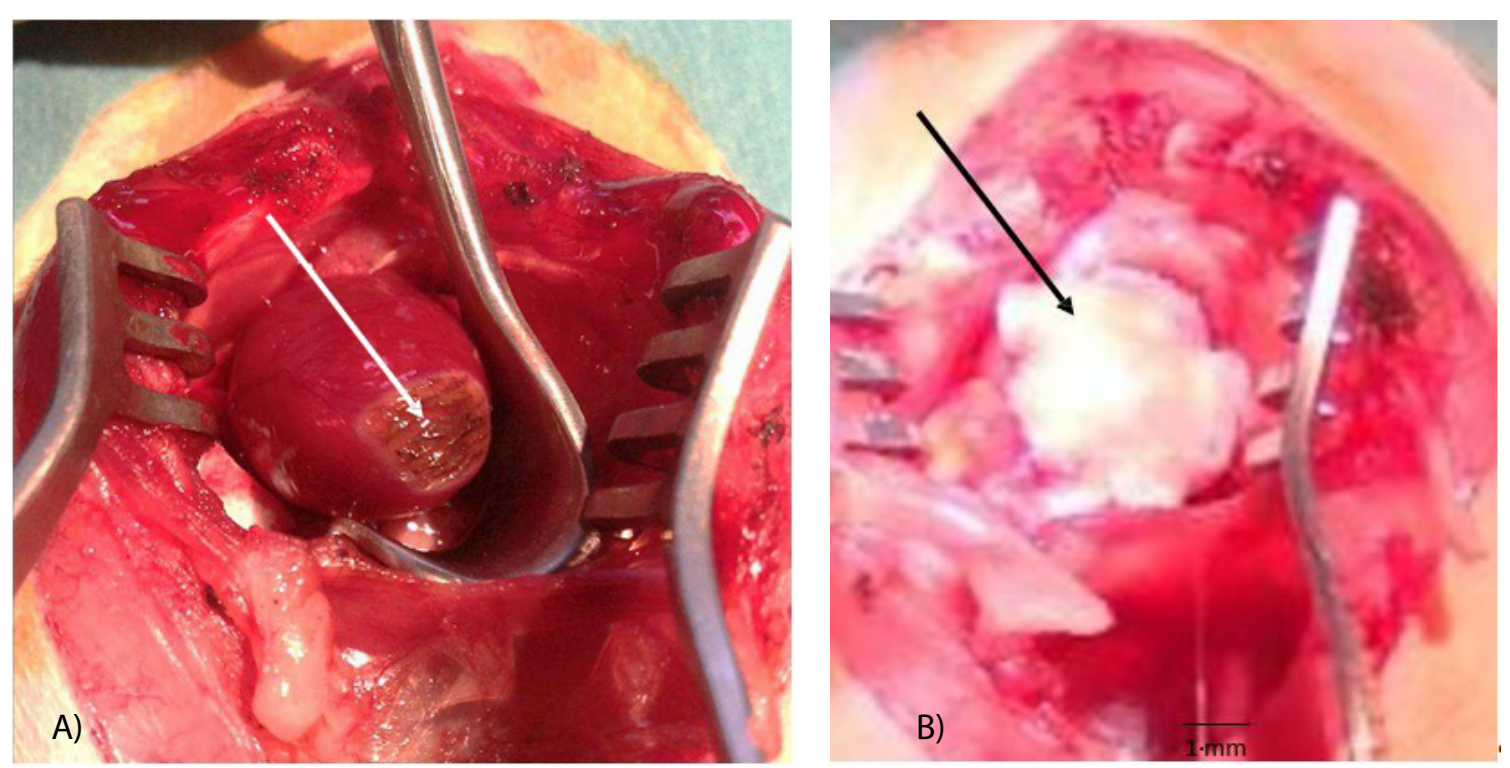

Figure 1: Surgical procedures.

A: Thermal lesion of the heart apex (arrow).

B: Fetal heart implant fixed by chitosan flap (arrow) in the lesion site.

Later, daily observation of the animals was realized up to 12 months after the operation; the animal Body Weight (BW) was measured at days 2, 5, 7, 14 and, after the initial BW recovering, once a month.

\section{Post-Operative investigations}

Electrocardiography (ECG): Before or after ultra sound investigation and before euthanasia ECG was recorded using the same "Mouse monitor" as during the operations. Heart rate and QRST complex characteristics were evaluated in comparison with the intact animal indices.

Echocardiography (USI): At days $10 \pm 2,30 \pm 5$, and later at 1.5, and $4,5,6,7,8,9$ and 12 months post-surgery, the animals were investigated using an ultrasound system IU22 (Philips-NL) with an ultrasonic probe (L17-5 MHz). 11 intact animals were also investigated and used as controls. Ejection fraction (EF) was determined by Simpson method. The Left Ventricle Wall Thickness (LVWT) was measured at the level of the lesion, the FHI and in the intact area of the heart. To test the intra observer variability during each investigation, each $\mathrm{EF}$ and LVWT measure was repeated 3-4 times and $\mathrm{M} \pm \mathrm{SD}$ values were calculated. Only results with a variability $<10 \%$ were accepted.

In order to avoid pain during echocardiography investigation of recently operated animals anesthesia by intra peritoneal injection of Pentobarbital Sodium (Nembutal ${ }^{\circ}: 0.1 \mathrm{ml} / 100 \mathrm{~g} \mathrm{BW}$ of a solution to $0.075 \mathrm{mg} / \mathrm{dl}$ ) was provided.

Histological investigation: In all series, after each animal death or euthanasia (anesthetic overdose), that is at days $0,1,2,5,7,14,21,28$, $35,37,42,60$ and at months 4, 6, 7-12, macroscopic and microscopic investigation of the transplantation area, the heart and main inner organs (lungs, liver, kidneys) was provided. Collected biopsy materials were fixed in neutral buffered formaldehyde $4 \%$ and embedded in paraffin. Three microns slices were stained by hematoxylin, eosin, saffron and by trichrome green of Masson for microscopic evaluation.

Statistics: The results are given as Mean \pm Standard Deviation (M \pm SD). The reproducibility of the measuring techniques was expressed as the coefficient of variation of repeated measurements $(\mathrm{V}=\mathrm{SD} / \mathrm{M}$ $\%)$. Statistical significance of differences was assessed by Student's test versus control series ( $\mathrm{td}<\mathrm{t}$ standard) and $\chi^{2}$ for comparison of distributions. Results were considered significant for $\mathrm{p} \leq 0.05$. In some series correlation between results was investigated. Besides, the statistic evaluation concerned not only the mean data of each series but also the comparison between the results obtained at days 10 and 30 in the same animal (paired results).

\section{Animal's management}

Before, during and after the experimentation animals were managed according to the rules instruction of Belgian CEBEA 2013. Taking into account the importance of the surgery and its possible consequences, for instance in competition for food, the animals were kept in individual cages type 3.The nutrition conditions were standardized all through the experiment with the use of "food for breeding" (AO4, "Safe"; France) and of fresh water as drink.

The experiments were authorized by the local Committee of Animal Welfare (protocol $\mathrm{N}^{\circ} 508$ ).

\section{Results}

The global results of the main series are presented in tables 2 and 3.

The lesion depth was always $1-1.5 \mathrm{~mm}$ that is the inner muscle layer was viewed on the wound bottom.

As seen in table 2 absence of significant differences between the basic conditions of the different experimental series was ensured (that could allow a valuable comparison of the investigation results).

\section{The heart apex standard thermal lesion}

The heart apex standard thermal lesion was well tolerated. 100 animals out of 118 survived the first three post-operative days. The most frequent cause of early death was haemorrhage and ARCA. The animals surviving remained active in spite of slight BW loss which was not significant. However, the expected body weight gain for male rats 
Table 2: Compared experimental conditions in main series ( $M \pm S D)$.

\begin{tabular}{|c|c|c|c|c|c|c|}
\hline Series & $\begin{array}{c}\text { Adult rat initial } \\
\mathrm{BW}(\mathrm{g})\end{array}$ & $\begin{array}{c}\text { Adult rat } \\
\text { terminal BW }(\mathrm{g})\end{array}$ & $\begin{array}{l}\text { Surgery time } \\
\text { (min) }\end{array}$ & $\begin{array}{c}\text { Lesion initial } \\
\text { diameter* }(\mathrm{mm})\end{array}$ & Donor BW (g) & $\begin{array}{l}\text { Implant Ischaemia } \\
\text { time (min) }\end{array}$ \\
\hline Lesion only ( $n=24)$ & $403 \pm 55$ & $392 \pm 70$ & $28.9 \pm 19$ & $7.6 \pm 1.6$ & NA & NA \\
\hline Lesion+feutre $(n=13)$ & $414.2 \pm 53.6$ & $410 \pm 33$ & $33.42 \pm 8.3$ & $7.64 \pm 1.2$ & NA & NA \\
\hline Lesion+chitosan $(n=13)$ & $425 \pm 62$ & $449 \pm 38$ & $30.7 \pm 6.6$ & $7.33 \pm 1.1$ & NA & NA \\
\hline Total: Lesion+cover $(n=26)$ & $419 \pm 71$ & $431 \pm 70$ & $31.0 \pm 11.13$ & $7.5 \pm 103$ & NA & NA \\
\hline Lesion+FHI+Feutre or Contegra $(n=19)$ & $440.6 \pm 20$ & $436 \pm 20$ & $35.4 \pm 3.7$ & $7.5 \pm 0.66$ & $2.88 \pm 2$ & $9.2 \pm 3.7$ \\
\hline Lesion+FHI+chitosan ( $n=15)$ & $410.6 \pm 65$ & $395 \pm 40$ & $37.9 \pm 13$ & $7.18 \pm 0.36$ & $2.5 \pm 1.4$ & $11.15 \pm 1.6$ \\
\hline Total: Lesion+FHI ( $n=37)$ & $407 \pm 41$ & $419 \pm 71$ & $32.75 \pm 7.9$ & $7.64 \pm 0.98$ & $2.75 \pm 1.67$ & $10.6 \pm 1$ \\
\hline
\end{tabular}

Table 3: Global results of orthotopic foetal heart implantation on lesion site.

\begin{tabular}{|l|c|c|c|c|}
\hline \multicolumn{1}{|c|}{ Series } & Number of rats & Recipient survival >day $\mathbf{3}$ & Early complications <day $\mathbf{3}$ & Late complications \\
\hline Lesion only & 43 & 34 & 9 (ARCA, haemorrhage) & Aneurysm - 3 \\
\hline Lesion+covering & 37 & 35 & (anesthesia overdose) & Aneurysm - 1 \\
\hline Lesion+covering+FHI & 38 & 31 & (ARCA, haemorrhage) & $\mathbf{1 8}$ \\
\hline Total & $\mathbf{1 1 8}$ & $\mathbf{1 0 0}$ & $\mathbf{7}$ \\
\hline
\end{tabular}

*Foetus - donors aged 12-14 days, $\mathrm{BW}<1 \mathrm{~g}$.

depending on age was only rarely observed. In the long run, 4 of the rats with an uncovered lesion or a covering without FHI developed an aneurysm. No aneurysm was observed in the animals who had received a FHI, but 3 of them developed a teratoma.

ECG alterations: ECG alterations developing within the first minutes following the heart standard cauterization were typical for an acute infarct; QRS enlargement, ST lowering or elevation superior to 2 divisions $(20 \mathrm{~Hz})$. Later ECG alterations turned typical for chronic heart fibrosis: deep Q wave, low T wave, sometimes persistent elevated ST segment, without further changes (Figure $2 \mathrm{~A}$ ).

US investigations: US investigations at different time points following the lesion (Table 4) have confirmed the functional impairment. The heart rhythm had a tendency to increase in the first days but soon turned back to ranges close to control. Ejection Fraction (EF) reduction in comparison with intact control was significant $(\mathrm{p}<0.001$ and $<0.01$; mean EF decrease constituted $38.3 \%$ of the control value at day 10 and $27.3 \%$ at day 28)). Later, mean EF deficit progressively reduced but remained significant after 6 and 12 months (minus 13-16\%, p <0.01). EF values higher than 69\% were never observed in rats with an untreated lesion (Figure 2B).

Heart wall thickness in systolic phase at the lesion level was significantly decreased only at day $10(\mathrm{p}<0.05)$ comparatively to the intact area and to the values obtained in the control animals. Wall thickness then improved at the end of the first month and normalized later, except if an aneurysm developed (Table 4A). In 3 cases at day 10, 31, 41 a thin $\mathrm{LV}$ wall corresponded to aneurysm formation visually and histologically confirmed.

The distribution of the EF's measured after the lesion was highly significantly different $(\mathrm{p}<0.001)$ in the rats with an untreated lesion than in their control counterpart.

Histological evolution: Histological evolutions of the lesions are presented on figure $2 \mathrm{C}$. At day 0 , an important tissue edema, signs of myocytes suffering (shrunk nuclei, disappearance of muscle striation, intra-cellular edema, coagulation, and necrosis), activation of capillary endothelium and an inflammatory reaction start were observed (Figure 2C-1). During the following days, both degenerative and inflammatory reactions increased. A coagulum was present at the injury level. At day 14, mild fibrosis appeared.

After 1 month, the coagulum underwent near complete phagocytic destruction; the fibrosis zone was well organized with oriented fibers, sometimes penetrating the healthy part of the myocardium (Figure $2 \mathrm{C}-2,2 \mathrm{C}-3$ ). In 3 cases the fibrosis was transmural and an aneurysm was formed. In 2 cases formation of cartilage into the trabecular muscle was observed (as a transformation of the myocytes) in the neighboring of the lesion. At a small distance from the injured zone and in the remaining intact parts of the heart, the myocardium looked quite normal. Later, up to 8 months, marked fibrosis occupied the lesion area. Other organs-lungs and liver-remained normal.

\section{After heart apex lesion and immediate FHI under different material covers}

After Heart Apex Lesion and immediate FHI under different material covers felt and contegra were quite neutral, did not cause inflammatory reaction but were too rigid, did not degrade and compressed the graft, with a decrease of EF from 58 to $50 \%$ between 1 and 2-4 months (supplementary material).

Chitosan, as a degradable material, resorbed completely after 4 months. Thus, only results where chitosan was used, were taken into account in further analysis.

General condition and BW were satisfactory during the whole observation period, but the expected weight increase for Wistar male did not occur.

ECG alterations: During the first days and months ECG alterations remained typical for infarct. However, at 4, 6 and 8 months, normal ECG could be registered in some animals (Figure 3A). 
Table 4A: Main functional results of heart lesion series according to Ultra Sound Investigation. Mean values depending on observation delay.

\begin{tabular}{|c|c|c|c|c|c|c|}
\hline \multirow{2}{*}{ Series } & \multirow{2}{*}{$\begin{array}{c}C R \\
(M \pm S D)\end{array}$} & \multirow{2}{*}{$\begin{array}{c}\text { Ejection Fraction in \% (loss } \\
\text { relatively to control) }\end{array}$} & \multicolumn{2}{|c|}{ Intact wall (mm) } & \multicolumn{2}{|c|}{ Lesion site (mm) } \\
\hline & & & Systole & Diastole & Systole & Diastole \\
\hline \multicolumn{7}{|l|}{ Lesion only } \\
\hline 10 d. $N=11$ & $421 \pm 32$ & $45.58 \pm 9.5(38.3 \%)$ & $3.32 \pm 0.22$ & $2.12 \pm 0.40$ & $2.85 \pm 0.2^{*}$ & $2.05 \pm 0.1$ \\
\hline 1 mo. $\mathrm{N}=11$ & $385 \pm 48$ & $56.3 \pm 9.5^{*}(27.3 \%)$ & $3.47 \pm 0.33$ & $2.66 \pm 0.23$ & $3.07 \pm 0.36$ & $2.7 \pm 0.3$ \\
\hline $2-6$ mo. $\mathrm{N}=13$ & $393.5 \pm 53$ & $61.8 \pm 7.4(16.3 \%)$ & $3.23 \pm 0.16$ & $2.35 \pm 0.15$ & $3.3 \pm 0.35$ & $2.43 \pm 0.36$ \\
\hline $6-12 \mathrm{mo} . \mathrm{N}=9$ & - & $63.87 \pm 4.5(13.6 \%)$ & $3.25 \pm 0.26$ & $2.41 \pm 0.3$ & $3.3 \pm 0.36$ & $2.58 \pm 0.3$ \\
\hline Intact control $\mathbf{N}=\mathbf{2 3}$ & $394 \pm 12$ & $73.9 \pm 5.3$ & $3.28 \pm 0.0 .1$ & $2.34 \pm 0.1$ & NA & NA \\
\hline
\end{tabular}

Table 4B: Main functional results of heart lesion series according to Ultra Sound Investigation.

Ejection fraction (EF) values frequency distribution (pool of all measurements during follow up) ( 24 sur 44 cases of EF>60\%, that is $54.5 \%$ of recovery).

\begin{tabular}{|c|c|c|c|c|c|c|c|}
\hline EF values /time & Observation Number & $<40$ & $40-50$ & $50-60$ & $60-70$ & $70-80$ & $>80$ \\
\hline Day $10 \pm 2$ & 11 & 3 & 5 & 2 & 1 & & \\
\hline Day $30 \pm 9$ & 11 & & 3 & 3 & 5 & & \\
\hline Month 2-5 & 13 & & 2 & 1 & 10 & & \\
\hline Month 6-12 & 9 & & & 1 & 8 & & \\
\hline Total & 44 & 3 & 10 & 7 & 24 & 0 & 0 \\
\hline Total control & 23 & & & & 7 & 14 & 2 \\
\hline
\end{tabular}

Heart rhythm was increased soon after the surgical intervention but later normalized.

Except during the operation, we never observed any abnormal rhythm disorder linked with an autonomous growing fetal heart implant activity.

US investigations: As USI investigation have shown, the implant was present and growing progressively (Figure 3B-1, 3B-2). At day 10 a significant transient decrease of EF was noted (Table 5). In the series with FIH and chitosan cover $80.6 \%$ of the animals "normalized" their EF at the end of the observation period (Table 5, Figure 3B3). Distribution of the EF values has shown that though significant difference from the intact control persisted, recovery started the most early in the series $\mathrm{L}+\mathrm{FHI}+\mathrm{C}$ with $\mathrm{EF}$ values the closest to the intact control (see figure 3B-2). During the first weeks after the operation the LVW thickness in the lesion area was significantly increased in systole as well as in diastole $(\mathrm{p}<0.01)$. This increase was progressive and stopped after 4 months probably due to chitosan degradation and disappearing (Figure 3B-2 and 3C, Table 5A).

In this series no case of aneurysm were detected, but 3 cases of a teratoma growth was observed and histologically confirmed. These cases were, observed when donors were aged only 12-14 days intra utero development with a body weight $\leq 1 \mathrm{~g}$ [35].

Histological evolution: Histologically, at day 3 the implant with its basophilic cardio myoblasts was detected between injured myocardium and chitosan or other cover. (Figure 3C-1, 3C-2, 3C-3). Apoptotic cells, erythrocytes and oedema surrounded cardio myoblasts in good condition.

At day 30, the implant was still characterized by basophilic cells in contact with the recipient myocardium without evidence of mutual penetration (Figure 3C-4, 3C-5). At month 2-4 the picture was the same, remnants of chitosan were observed. In several cases, at 4-5 months or later, it was no more possible to identify with precision the implant myocytes: only their chaotic disposition allowed suspecting their donor's origin (Figure 3C-6, 3C-7).

\section{After heart apex lesion covered only by chitosan sheet}

After heart apex lesion covered only by chitosan sheet, the results did not differ from the previous two series immediately after operation. Later, the recovery, though present in some cases, was not significant.

ECG alterations \& US investigations: Both ECG and EF did not reached complete normalization though the mean $\mathrm{EF}$ values were no more significantly different from normal control in late delays (Figure 4 A, Table 6).

1 case of aneurysm at month 6 was observed inspite of felt/fedora cover and 1 case of deep FE fall $(<50 \%)$ at month 3 .

Histological evolution: Histologically chitosan was completely degraded after 2-5 months. In the lesion site covered with chitosan an inflammatory reaction was noted during the whole period of the biomaterial degradation. So, numerous capillaries, micro veins and arterioles were observed in this area (Figure 4B). In late delays fibrous scar has developed on the lesion site.

\section{Discussion}

First of all, we think necessary to point some limits of the present work design which have to be taken into account in the analysis and interpretation of our results.

Animal model: The rat is known to have a high ability of tissue self-regeneration and functional compensation. This may explain the relatively weak differences in the degree of functional rehabilitation between different series especially at the end of the observation period.

Surgery: Only immediate repair after the lesion was performed. In some recipients we tried delayed FHI but the re-operation was technically complicated because of adherences, and poorly tolerated by the recipients.

It may be the objective of further works.

Investigations: Functional investigation using ultra sound is especially difficult in the rat because of 1 ) the rapid heart rate (300$450 / \mathrm{min})$, 2) the peculiarities of EF determination by the Simpson 

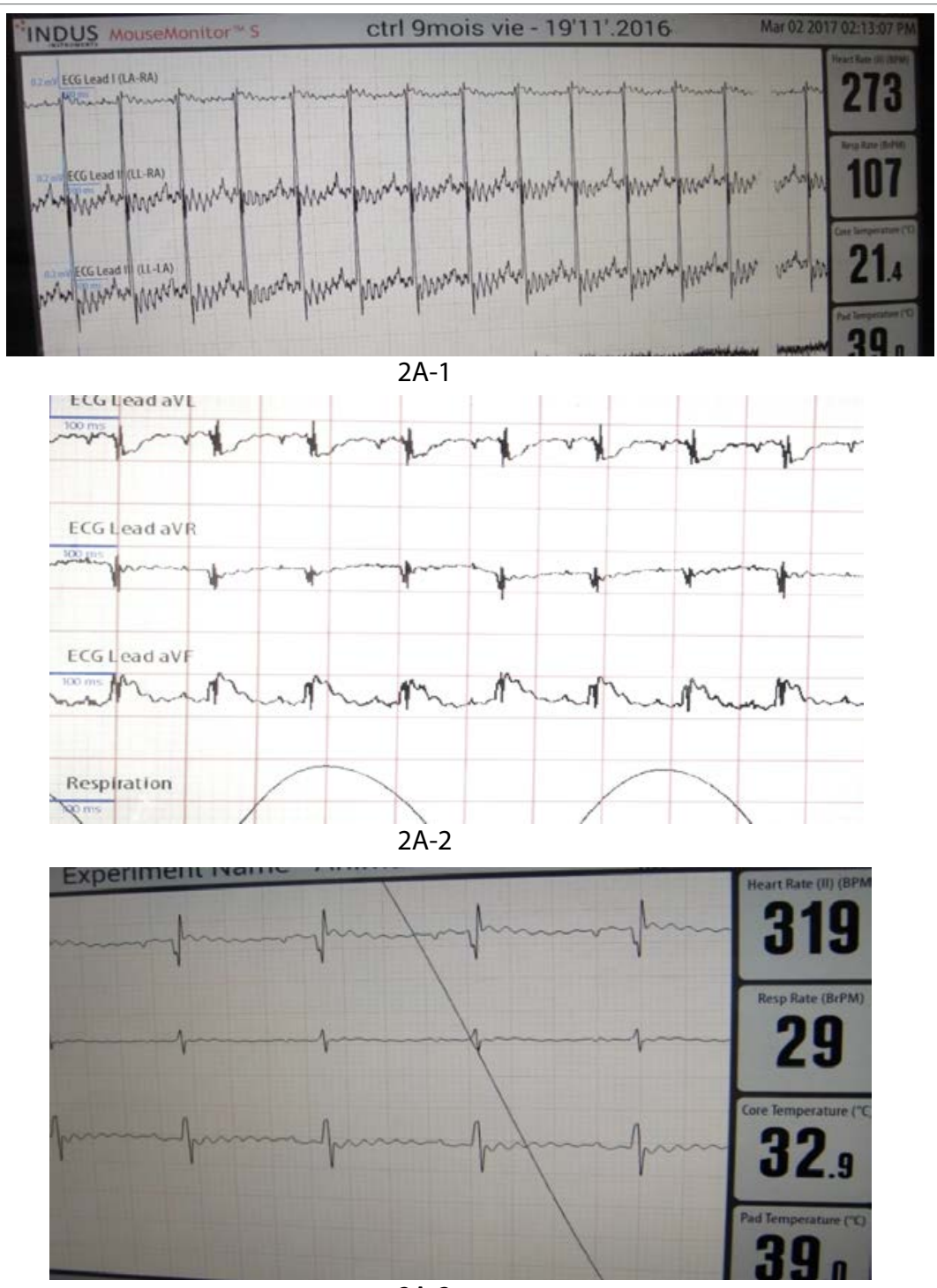

$2 \mathrm{~A}-3$

Figure 2: Functional and morphologic evolution of the heart after thermic apical lesion.

2A: ECG.

2A-1: Control ECG in healthy anesthetized rat.

2A-2: ECG within 30 min after surgery: Signs of acute infarct (ST segment under or above the basis line).

2A-3: ECG within one year after surgery: signs of chronic infarction (deep $Q$ wave in one or more derivations).

method and 3) the resolution limits of the US probe and device. These difficulties were overcome by the operator's skill in determination of systole and diastole maximal level and repeated measures which variability did not exceeded $10 \%$ of the mean. Individual reaction to anaesthesia and influence of the delay between its initiation and the investigation moment on the heart activity (beating rate) are also to be mentioned as possible causes of difficulties when comparing results of EF investigation.

In spite of these limitations, the results allow to draw some facts and considerations, which may be discussed. Several studies have shown that fetal heart implants could develop and function in the anterior eye chamber and within a subcutaneous pouch at the ear site $[29,30]$. Flaps of grown fetal stomach and esophagus implants were successfully used in combined bio prosthesis for circular esophageal defect repair [33]. However in the present preliminary experiments vascularized flaps of grown FHI could not be used to repair heart lesion, because 1) sufficient fetal heart growth was obtained only at ear pavilion, neck or thymus sites (and not in lung hila, mediastinum or omentum majus, as expected), 2) the implant was too distant from the heart apex infarct to be used as a vascularized flap for its repair. So this approach was not available.

The second approach discussed in the present study i.e., direct implantation of FHI into the lesion site, has proved feasible and promising.

Significant alterations of functional and morphological parameters after the thermal lesion of the heart apex were present in all series especially during the first 10-12 days. They result from the observed interstitial edema and cardiomyocytes necrosis that limited the functional capacities of the heart (infarct). The formation of a coagulum did not prevent an inflammatory reaction to develop rapidly with an 

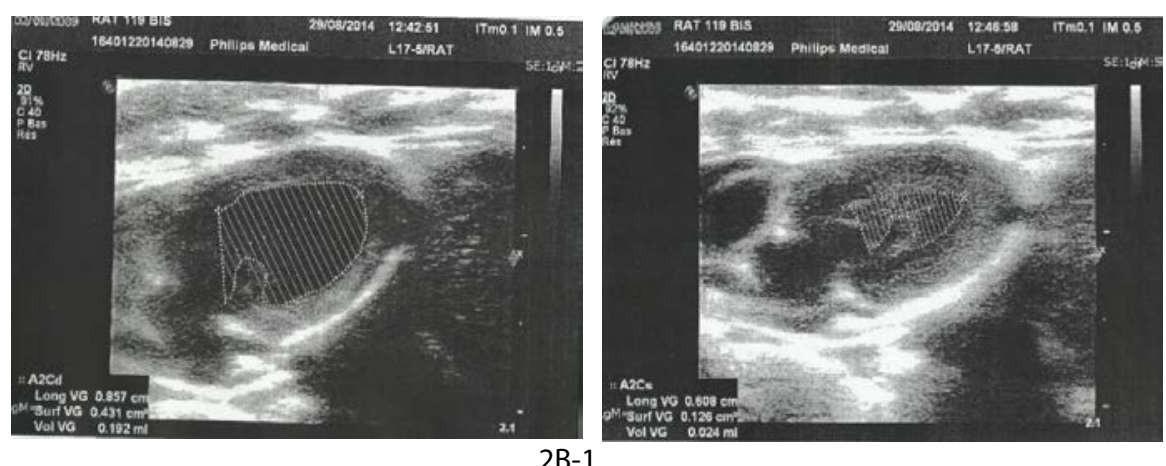

2B-1
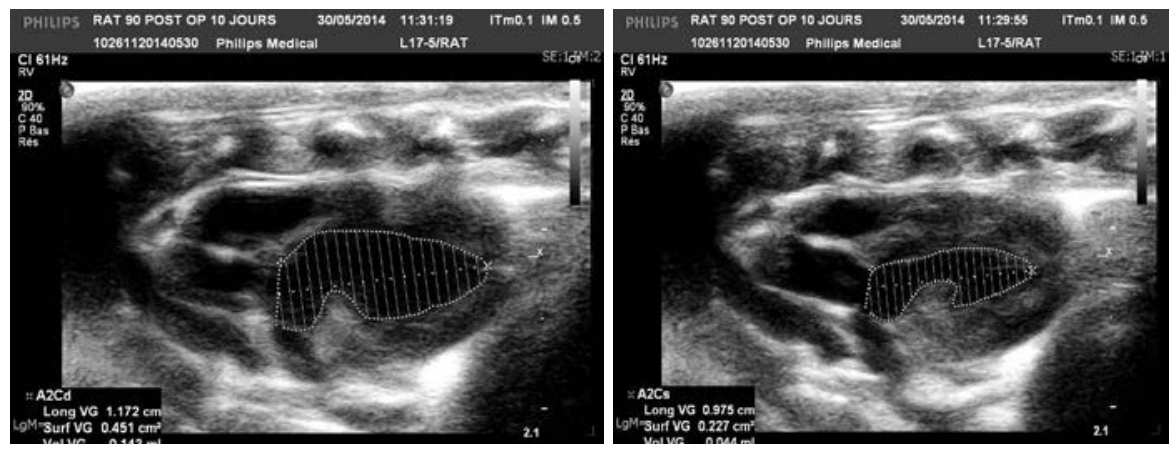

2B-2

Figure 2: Functional and morphologic evolution of the heart after thermic apical lesion.

2B: USI.

2B-1: Control Ejection Fraction determination by Simpson method in healthy rat.

2B-2: EF reduction after 1 month post-surgery.

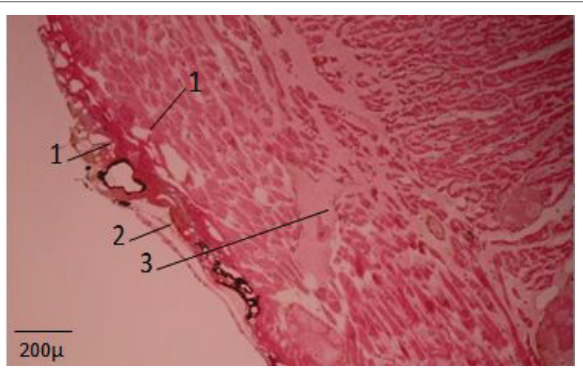

$2 \mathrm{C}-1$

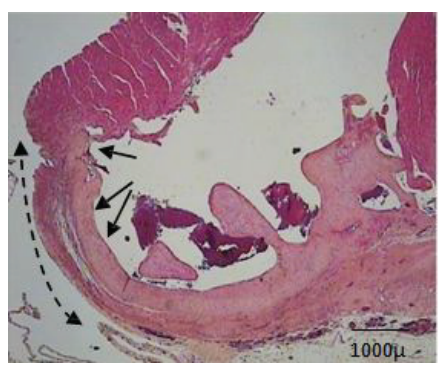

$2 \mathrm{C}-2$

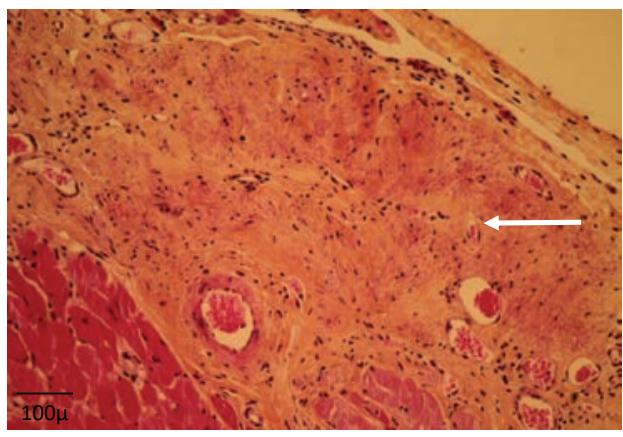

$2 \mathrm{C}-3$

Figure 2C: Histology (haematoxylin, eosin, saffron).

2C-1: Day 2: Vapour bubbles (1), coagulum (2), cardiomyocyte necrosis (3).

2C-2: Day 30: Fibrosis of the myocardium apex (arrows).

2C-3: Month 8: Fibrosis at the lesion site (arrow). 
Table 5A: Main functional results in series Lesion+FHI+chitosan cover according to Ultra Sound investigation. Mean values depending on observation delay.

\begin{tabular}{|c|c|c|c|c|c|c|}
\hline \multirow{2}{*}{ Series } & \multirow{2}{*}{$\begin{array}{c}C R \\
(M \pm S D)\end{array}$} & \multirow{2}{*}{$\begin{array}{c}\text { Ejection Fraction in \% } \\
\text { (loss relatively to control) }\end{array}$} & \multicolumn{2}{|c|}{ Intact wall (mm) } & \multicolumn{2}{|c|}{ Lesion site (mm) } \\
\hline & & & Systole & Diastole & Systole & Diastole \\
\hline \multicolumn{7}{|l|}{$\mathrm{L}+\mathrm{C}+\mathrm{FHI}$} \\
\hline 10 d. $N=5$ & $412.5 \pm 23.5$ & $56.07 \pm 1.9 * *(24.1 \%)$ & $3.42 \pm 0.23$ & $2.5 \pm 0.2$ & $4.97 \pm 0.3^{*}$ & $4.25 \pm 0.2^{*}$ \\
\hline $1 \mathrm{mo} . \mathrm{N}=7$ & $400 \pm 33$ & $69 \pm 5 *(-6.6 \%)$ & $3.4 \pm 0.2$ & $2.497 \pm 0.6$ & $4.55 \pm 0.74^{*}$ & $4.05 \pm 0.73^{* *}$ \\
\hline 2- $4 \mathrm{mo}$ & $360 \pm 10$ & $66.3 \pm-4.7^{*}(-10.2 \%)$ & $3.05 \pm 0.2$ & $2.53 \pm 0.31$ & $5.23 \pm 1.0 * *$ & $4.2 \pm 0.66^{* *}$ \\
\hline$N=10$ & $386.6 \pm 13.3$ & $64.8 \pm 6.2(-12.3 \%)$ & $3.4 \pm 0.2$ & $2.6 \pm 0.2$ & $4.7 \pm 0.2^{* *}$ & $3.85 \pm 0.36^{* *}$ \\
\hline $6-8 \mathrm{mo} . \mathrm{N}=6$ & $341 \pm 13.3$ & $65.1 \pm 6^{*}(-11.9)$ & $3.66 \pm 0.28^{*}$ & $2.7 \pm 0.4$ & $4.1 \pm 0.2^{*}$ & $3.3 \pm 0.2^{*}$ \\
\hline $9-12$ mo. $N=6$ & - & - & - & - & - & - \\
\hline Intact control $\mathrm{N}=23$ & $394 \pm 12$ & $73.9 \pm 5.3$ & $3.28 \pm 0.01$ & $2.34 \pm 0.1$ & NA & NA \\
\hline
\end{tabular}

$* p<0.05 ; * * p<0.001$

Table 5B: EF values frequency (pool of all measurements during follow up) (25 cases $>60 \%$ out of 31 that is $80.5 \%$ of recovery). Main functional results in series Lesion+FHI+chitosan cover according to Ultra Sound investigation.

\begin{tabular}{|c|c|c|c|c|c|c|c|}
\hline EF values/time & Observation number & $<40$ & $40-50$ & $50-60$ & $60-70$ & $70-80$ & $>80$ \\
\hline Day $10 \pm 2$ & 4 & & & 4 & & & \\
\hline Day 30 & 7 & & & & 5 & 2 & \\
\hline Month 2-5 & 10 & & & 2 & 4 & 4 & \\
\hline Month 6-12 & 12 & & & 2 & 8 & 2 & \\
\hline Total & 31 & 0 & 0 & 8 & 17 & 8 & \\
\hline Total control & 23 & & & & 7 & 14 & 2 \\
\hline
\end{tabular}

Table 6A: Functional results in series lesion+chitosan alone according to Ultra Sound investigation.

Mean values.

\begin{tabular}{|c|c|c|c|c|c|c|}
\hline \multirow{2}{*}{ Series } & \multirow{2}{*}{$\begin{array}{c}C R \\
(M \pm S D)\end{array}$} & \multirow{2}{*}{$\begin{array}{c}\text { Ejection Fraction in \% } \\
\text { (loss relatively to control) }\end{array}$} & \multicolumn{2}{|c|}{ Intact wall (mm) } & \multicolumn{2}{|c|}{ Lesion site (mm) } \\
\hline & & & Systole & Diastole & Systole & Diastole \\
\hline \multicolumn{7}{|c|}{ Lesion+Chitosan } \\
\hline 10 d. $N=4$ & $414 \pm 53.6$ & $54.7 \pm 2.0(-20.8 \%)$ & $3.22 \pm 0.23$ & $2.36 \pm 0.13$ & $4.22 \pm 0.56$ & $3.5 \pm 0.53$ \\
\hline $1 \mathrm{mo} . \mathrm{N}=6$ & & $65 \pm 4.1 *(19.9 \%)$ & $3.46 \pm 0.25$ & $2.66 \pm 0.23$ & $3.18 \pm 0.66$ & $2.55 \pm 0.5$ \\
\hline $2-4$ mo. $\mathrm{N}=11$ & $416 \pm 58.6$ & $63.7 \pm 3.7(13.8 \%)$ & $\mathrm{nm}$ & & $\mathrm{nm}$ & \\
\hline $6-8 \mathrm{mo} . \mathrm{N}=8$ & & $65.09 \pm 7.3(-11.9 \%)$ & $3.51 \pm 0.33$ & $2.65 \pm 0.16$ & $3.91 \pm 0.4$ & $3.2 \pm 0.43$ \\
\hline $\begin{array}{l}\text { Intact control } \\
\mathrm{N}=\mathbf{2 3}\end{array}$ & $394 \pm 12$ & $73.9 \pm 5.3$ & $3.28 \pm 0.01$ & $2.34 \pm 0.1$ & NA & NA \\
\hline
\end{tabular}

Table 6B: Functional results in series lesion+chitosan alone according to Ultra Sound investigation.

EF values frequency (pool of all measurements during follow up) (19 sur 29 so it 65.5\% recovery).

\begin{tabular}{|c|c|c|c|c|c|c|c|}
\hline EF values/time & Number of cases & $<40$ & $40-50$ & $50-60$ & $60-70$ & $70-80$ & $>80$ \\
\hline Day $10 \pm 2$ & 4 & & 4 & & & & \\
\hline Day $30 \pm 9$ & 6 & & & 2 & 3 & 1 & \\
\hline Day $30 \pm 9$ & 11 & & & 3 & 8 & & \\
\hline Month 6-12 & 8 & & & 1 & 6 & 1 & \\
\hline Total & 29 & 0 & 4 & 6 & 17 & 2 & \\
\hline Total control & 23 & & & & 7 & 14 & 2 \\
\hline
\end{tabular}

enhanced vascularization of the area, basis for the remodeling process. However this remodeling did not lead to a complete functional and morphologic repair. In our series in the absence of intervention only some improvement was obtained and the cardiac function remained significantly under the control level even in the late delays, probably because a stable fibrous scar involved the heart apex leading to aneurysm development in several cases.
Only immediate repair of the injured heart apex resulted in a clear functional and morphological benefit, already observed within the first 3-4 weeks. Combination of FHI and chitosan led to a rapid functional improvement, complete functional normalization in some cases, and global EF recovery in $80.9 \%$ (versus 70,65 , and $55 \%$ in other series). The distribution of EF was the most close to the intact control (see figure 3B-2). This improvement was also observed when a flap of 


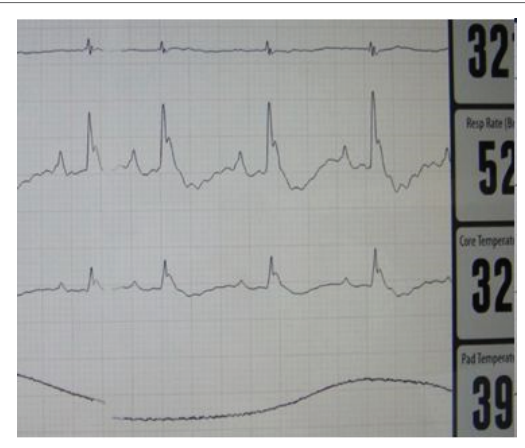

$3 \mathrm{~A}-1$

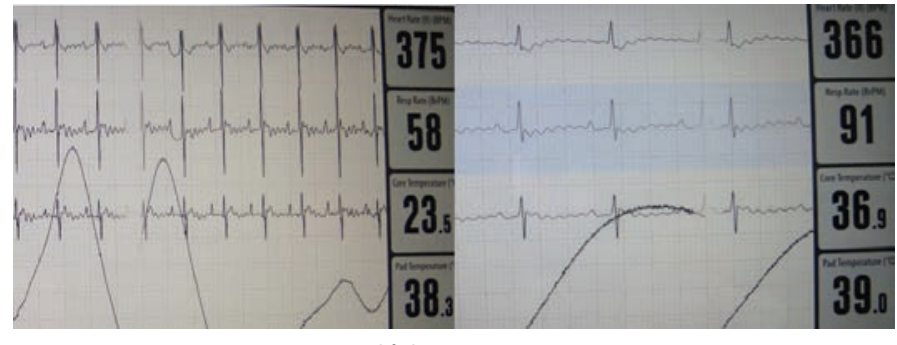

$3 \mathrm{~A}-3$

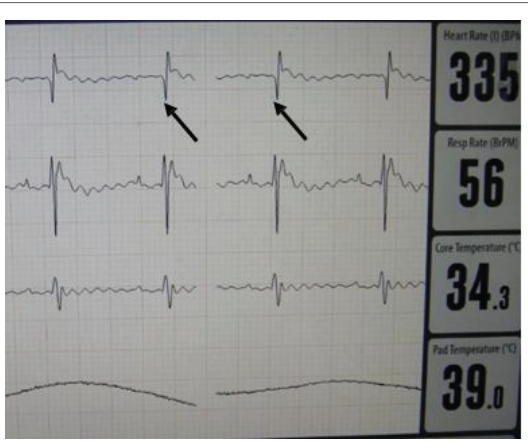

$3 \mathrm{~A}-2$

Figure 3A: Functional and morphologic evolution of the heart after thermic apical lesion covered by fetal heart implant fixed by chitosan flap. 3A: ECG.

3A-1: During operation: serious alterations of rhythm and form of the waves.

3A-2: At month 1: Signs of chronic infarct (deep Q waves).

3A-3: At months 4 and 8: Normalization of ECG in 2 animals.

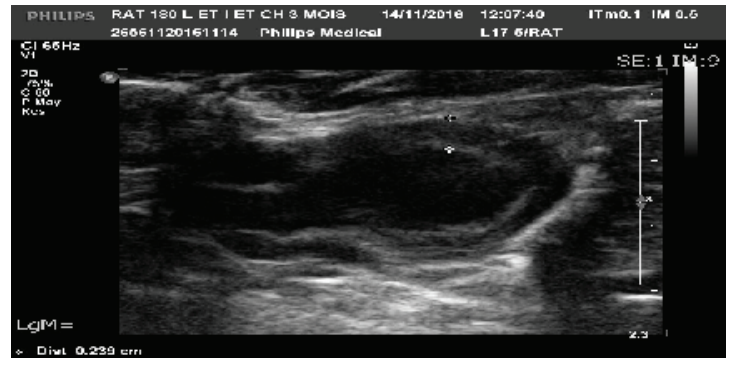

3B-1

\section{Distribution of EF's according to series}

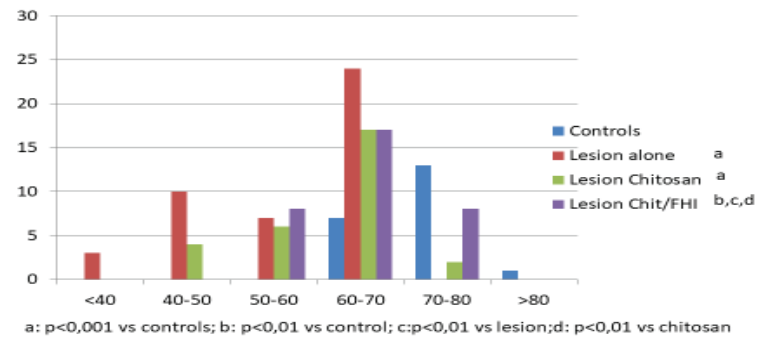

3B-2

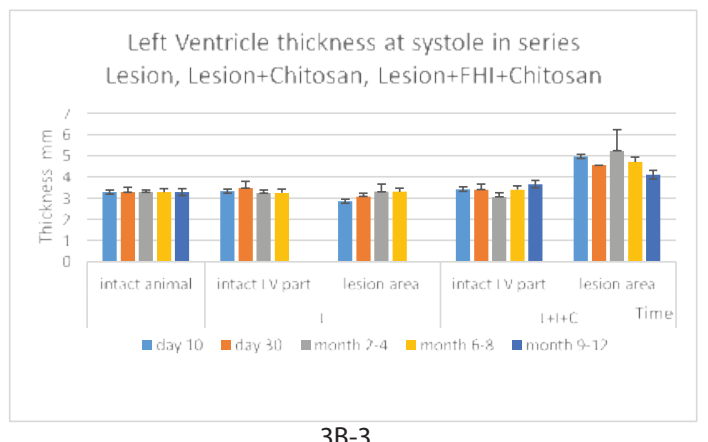

Figure 3: Functional and morphologic evolution of the heart after thermic apical lesion covered by fetal heart implant fixed by chitosan flap. 3B: USI.

3B-1: Month 3: The implant is viewed between +-- + with its chitosan cover.

3B-2: Significant increase of LVWT in all the observation delays in series with fetal heart implantation. 3B-3: Graphic of EF distribution between series. 


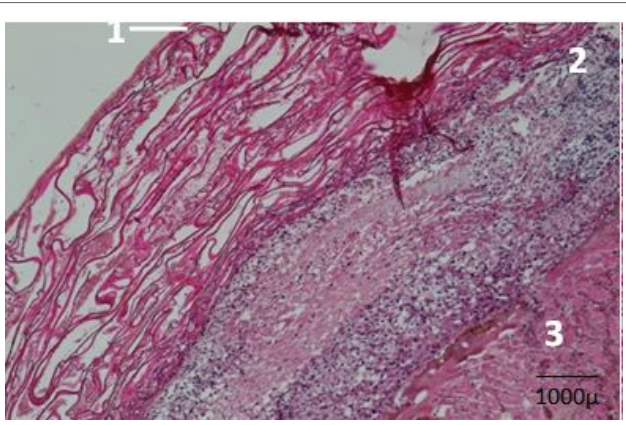

3B-1

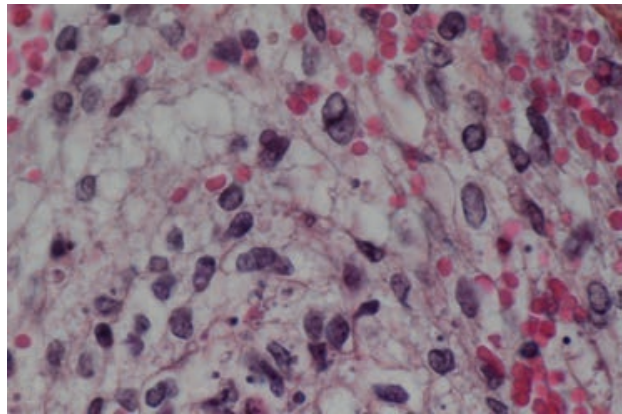

3B-3

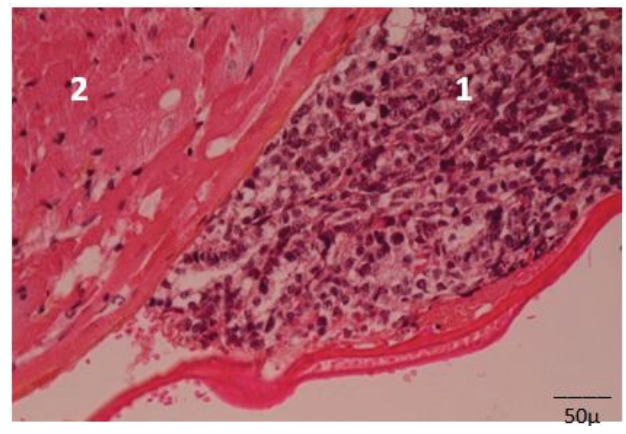

3B-5

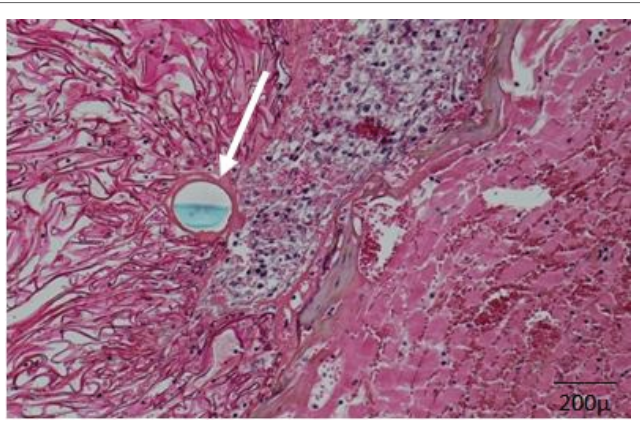

3B-2

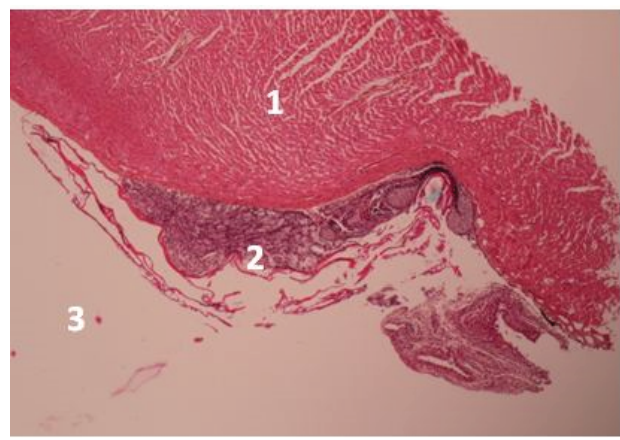

3B-4

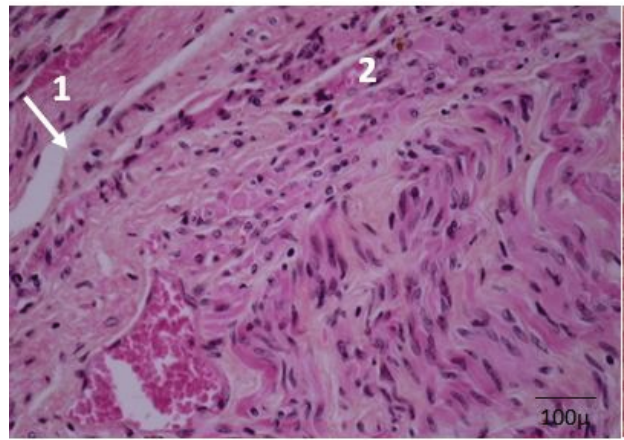

$3 B-6$

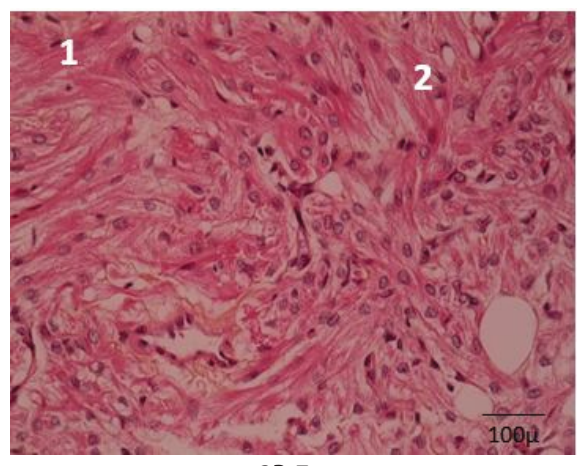

3B-7

Figure 3: Functional and morphologic evolution of the heart after thermic apical lesion covered by fetal heart implant fixed by chitosan flap. 3C: Histology (haematoxylin, eosin, saffron).

3C-1: Day 3: Injured myocardium (3) covered by fetal heart implant (2) fixed with chitosan flap (1).

3C-2: Idem: Suture through chitosan (arrow).

3C-3: Idem: Living and functioning cardiomyoblasts among apoptotic cells and erythrocytes.

3C-4: Day 30: The fetal heart implant (basophilic cardiomyoblasts (2)) is separated from recipient myocardium (1), chitosan remnants (3). 3C-5: Idem implant (1) with basophilic cells and injured recipient myocardium (2).

3C-6: Month 4-5: Recipient myocardium (1) in tight contact with the fetal heart implant (2) in some places (arrow) NB no infarct under the graft. 3C-7: Mature cardiomyocytes with only different organization for recipient (1) and donor (2) origins. 
chitosan or neutral material was used alone to cover the injury, but it was much less significant. So both components seemed to have an influence on the obtained positive results.

Role of the FHI: Independently on the covering material used, the EF normalization percentage obtained was much higher, when implant was present, than in series without FHI.

The FHI growth and development was confirmed by US detecting an increasing of LVW thickness in the repaired ventricular area. Histological pictures have shown, in the area of the FHI growth, the presence of living, functional recipient cardiomyocytes in spite of fibrosis. Interesting to note a tendency of the intact myocardium of the injured heart to increase in thickness in comparison with intact animals at month 9-12 when chitosan was totally resorbed.

We did not observe, after orthotopic FHI, adult like cardiac formations able to beat and ensure a blood flow through them, as shown in our previous experiences with FHI under the ear pavilion skin or described by authors working with stem cell implantation $[23,30]$. We could observe only differentiation of cardio myoblasts into cardiomyocytes which seemed in some cases seemed to infiltrate the recipient myocardium along fibrous expansions. However: as far as we used a syngeneic transplantation model to avoid immunologic conflict, we could not distinguish the donor and recipient cells. So we cannot precise the fate of the FHI, which could have had only a role to support the development of recipient cardiomyocytes. The absence of organoid development can explain that no rhythm perturbation was recorded after FHI.

Role of the covering material: The role of the materials fixing the implant in place has also to be mentioned, because the functional results of their use were intermediary between those of control and FHI series.
Though felt/fedora and Contegra are known neutral materials widely used in cardiac surgery, in our experiments their use (both alone and with FHI) have given worse results than those observed in the corresponding chitosan series. This is probably due to the persistence of the non resorbable material that limited the development of both myocardium remodeling and implant development.

The chitosan membrane positive influence on the injured myocardium remodeling may be explained by the inflammatory reaction accompanying the biodegradation of chitosan [33,34]. This increased the vascularization of the zone and so, may enhance the graft development as well as the heart remodeling.

This observation may be important because, up to now the use of FHI in the clinics cannot be proposed because of unsolved ethic problems; thus the use of a chitosan flap to cover an infarcted area might be a relatively easy manipulation (realized by thoracic endoscopy during the acute period of a vascular heart event or somewhat later).

Several questions remain open, such as:

- What were the mechanisms of FHI influence on the injured heart repair: growth factors secretion and stimulation, mobilization of the recipient stem cells?

- What was the role of inflammation (due to the lesion and chitosan degradation) as a trigger not only for FHI survival and development but also for mobilization of the host stem cells and their participation to the repair process?

- Does the implant really integrate the host myocardium and merge with it improving its functional ability and/or its regeneration potential?

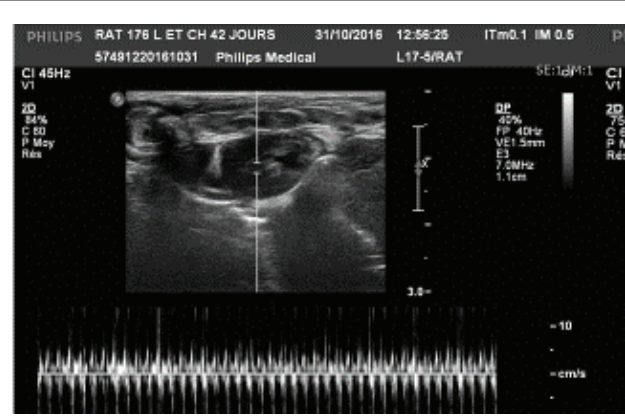

A
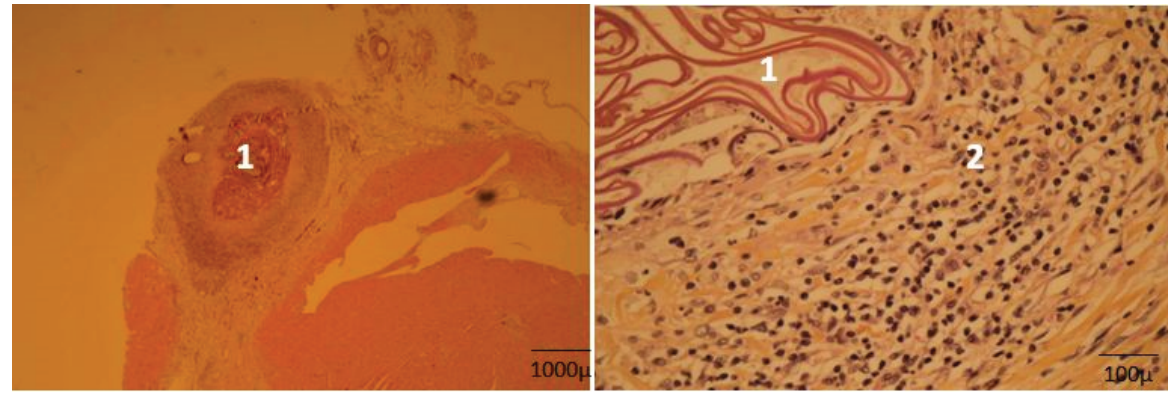

Figure 4: Functional and morphologic evolution of the heart after thermic apical lesion covered only by chitosan flap.

4A: USI: Month 3: The chitosan cover is viewed on the apex.

4B: Histology: Month 8: chitosan islet (1), mild inflammation around chitosan (2). 
- What would be the result of an FHI implantation provided some weeks or months after the occurrence of the lesion? A trial in that direction has shown the difficulty and poor outcome of a second intrathoracic intervention on the rat with an injured heart with diminished $\mathrm{EF}$ and the continuation of such an investigation would need further special experiments.

Anyway, thanks to the serious advance made in creating immunologic "invisible" stem cell or precursor cell graft [36], new perspectives are open also for FHI development.

\section{Conclusions}

Orthotopic fetal heart syngeneic implantation under a chitosan cover provided immediately into the site of a myocardium thermal lesion is feasible and promising: it significantly improves the functional and morphological repair of the injured heart in rats.

Use of chitosan flap alone for acute heart lesion dressing in clinics might be envisaged as temporary or alternative solution to adult heart transplantation.

\section{Acknowledgements}

The authors express their thankfulness to:

The Foundation for Cardiac Surgery and the Institute of Pathology and Genetics for precious material and moral support,

Professors G. Primo, P. Wauthy and P. Bergmann (Foundation for Cardiac Surgery; CHU Brugmann, ULB) for scientific support,

To Ms V Maquet ("Kitozyme"company) and Professor A. Collige (ULg) for chitosan membranes procurement,

Mr A. Bekkouri Richa, Ms G van de Gucht, N Lopez for their kind technical help and support,

Ms M Leroy (IPG) and Mr J-L Kempeneers for important logistic support.

\section{Disclosures}

None

\section{References}

1. A Report from the American Heart Association (2017) Heart Disease and Stroke Statistics-2017 Update. Circulation 135: e146-e603.

2. Hund LL, Edwards LB, Dipchand Al, Goldfarb S, Stehlich J, et al. (2016) The Registry of the International Society for Heart and Lung Transplantation: Thirty-Third Adult Heart Transplantation Report -2016; Focus theme: primary indications for Transplant. J Heart Lung Transplant 35: 1158-1169.

3. World Health Organization (2004) The Global Burden of Disease. 2004 Update. Department of Health Studies and Informatics in the Information. Evidence and Research Cluster, Geneva, Switzerland.

4. Roger VL, Go AS, Lloyd-Jones DM, Benjamin EJ, Berry JD, et al. (2012) Executive summary: Heart disease and stroke statistics--2012 update, a report from the American heart association. Circulation 125: 188-197.

5. Cowie MR (1999) Annotated references in epidemiology. Eur J Heart Fail 1: 101-107.

6. Hunt SA, Baker DW, Chin MH, Cinquegrani MP, Feldman AM, et al. (2002) ACC and AHA Guidelines for the evaluation and management of chronic heart failure in the adult: executive summary. J Heart Lung Transplant 21: 189-203.
7. World Health Report (2012) Mortality estimates by cause, age, and sex. World Health Organization.

8. Delahaye F, Roth O, Aupetit JF, de Gevigney G (2001) Epidemiology and Prognosis of Cardiac Insufficiency. Arch Mal Coeur Vaiss 94: 1393-1403.

9. Mezhra MR, Goldstein DJ, Uriel N, Cleveland JC, Yuzefpolskaya M, et al. (2018) Two-year outcomes with a magnetically Levitated cardiac pump in heart failure. N Engl J Med 378: 1386-1395.

10. Mehta SR, Wood DA, Storey RF, Mehran R, Bainey KR, et al. (2019) Complete revascularization with multivessel $\mathrm{PCl}$ for myocardial infarction. N Engl J Med 381: 1411-1421.

11. Saidi RF, Hejazii Kenari SK (2014) Challenges of organ Shortage for transplantation: solutions and opportunities. Int J Organ Transplant Med 5: 87-96.

12. Fatullayev J, Samak M, Sabashnikov A, Weymann A, Mohite PN, et al. (2015) Non-heart beating donor heart transplantation: breaking the taboo. Med Sci Monit Basic Res 21: 153-156.

13. Doumouras BS, Alba AC, Foroutan F, Burchill LJ, Dipchand Al, et al. (2016) Outcomes in adult congenital patients undergoing heart transplantation. A systemic review and meta-analysis. J Heart Lung Transplant 35: 1337-1347.

14. Awad M, Czer LS, Hou M, Golshani SS, Goltche M, et al. (2016) Early denervation and later reinnervation of the heart following cardiac transplantation: A review. J Am Heart Assoc 5: e004070.

15. Schmuelle P, Benck U, Kramer BK, Yard BA, Zuckermann A, et al. (2018) Impact of Donor Core Body Temperature on Graft Survival after Heart Transplantation. Transplantation 102: 1891-1900.

16. Crossland DS, Jansen K, Parry G, Harper A, Perri G, et al. (2019) Outcome following heart transplant assessment in adults with congenital heart disease. Heart 105: 1741-1747.

17. Jaquet K, Krause KT, Denschel J, Faessler P, Nauerz M, et al. (2005) Reduction of myocardial scar size after implantation of mesenchymal stem cells in rats: what is the mechanism? Stem Cells Dev 14: 299-309.

18. Aghila Rani KG, Taruna Madan (2017) Uterine stem cells and their future therapeutic potential in regenerative medicine. Imaging stem cell transplant and cell-based therapy 153-174.

19. Singh RK, Gaikwad SM, Chatterjee S, Ray P (2013) The Holy Grail of regenerative medicine. Engineering in Translational Medicine 19-69.

20. Marks PW, Witten CM, Califf RM (2017) Clarifying stem-cell therapy benefits and risks. N Engl J Med 376: 1007-1009.

21. Chien KR, Frisen J, Fritsche-Danielson R, Melton DA, Murry CE, et al. (2019) Regenerating the field of cardiovascular cell therapy. Nat Biotechnol 37: 232-237.

22. Zakrzewski W, Dobrtzinski M, Szymonowicz M, Rybak Z (2019) Stem cells: past, present and future. Stem Cell Res Ther 10: 68.

23. Lebon B, Garcin I, Ménasché P, Vilquin JT, Audinat E, et al. (2003) Myoblasts transplanted into rat infarcted myocardium are functionally isolated from their host. Proc Natl Acad Sci U S A 100: 7808-7811.

24. Etzion S, Battler A, Barbash IM, Cagnano E, Zarin P, et al. (2001) Influence of embryonic cardiomyocyte transplantation on the progression of heart failure in a rat model of extensive myocardial infarction. J Mol Cell Cardiol 33: 1321-1330.

25. Yao M, Dieterle T, Hale SL, Dow JS, Kedes LH, et al. (2003) Long term outcome of fetal cell transplantation on post infarction ventricular remodeling and function. J Mol Cell Cardiol 35: 661-670. 
26. Sakakibara Y, Tambara K, Lu F, Nishine T, Nagaya N, et al. (2002) Cardiomyocyte transplantation does not reverse cardiac remodeling in rats with chronic myocardial infarction. Ann Thorac Surg 74: 25-30.

27. Li RK, Jia ZQ, Weisel RD, Mickle DA, Zhang J, et al. (1996) Cardiomyocyte transplantation improves heart function. Ann Thorac Surg 62: 654-660.

28. Quéron S, Coulic V, Stefanidis C, Delrée P, De Prez C, et al. (2014) An Alternative Technique for Heart Lesion in the Rat: A Step to Fetal Heart Implantation for Cardiac Tissue Repair Running Title: A New Technique of Heart Lesion in Rat. J Transplant Technol Res 5: 149.

29. Tucker DC, Snider C, Woods WT Jr (1988) Pacemaker development in embryonic rat heart cultured in oculo. Pediatr Res 23: 637-642.

30. Kulik VP, DeKoster E, Delrée P, Deltenre P, DePrez K, et al. (2005) Experimental comparative evaluation of the functional capacities of ectopically grown foetal organs. Russian Journal of Physiology 91 : 408-430.
31. Quéron S, Coulic V, Delrée P, Deprez C, Najar ES, Bergmann P (2015) Fetal Heart Transplantation; influence of some factors. ESOT P477.

32. Quéron S, Delrée P, Najar ES, DePrez C, Coulic V, et al. (2017) About the use of foetal heart implants for heart lesion repair in rats. ESOT P196.

33. Vandaele S, Najar ES, Delrée P, DePrez C, Maquet V, et al. (2018) Combined bio-prosthesis for oesophagus defect repair (Experimental study). EC Gastroenterology and Digestive System 5: 854-871.

34. Khor E, Lee YK (2003) Implantable applications of chitin and chitosan. Biomaterials 24: 2339-2349.

35. Coulic V, Mboti F, Quéron S, Urbanowicz M, DePrez C, et al. (2019) Once more about syngeneic foetal organ grafting and teratoma formation. Acta Scientific Gastrointestinal Disorders 2: 39-47.

36. Dreuse T, Gravina A, Wang D, Schrepfer S, Tediashvili G, et al. (2019) Hypoimmunogenic derivatives of induced pluripotent stem cells evade immune rejection in fully immunocompetent allogenic recipient. Nat Biotechnol 37: 252-258. 